\title{
İşitme Kayıplı Bireylerde Müzik Algısı
}

\author{
Çağla TÜRK*, Azize KÖSEOĞLU**, Selva ZEREN***
}

\section{$\ddot{O} \mathbf{z}$}

İşitme kaybı, işitme duyusunda meydana gelen yetersizlik durumudur. Müzikal algı ise müziğin algılanmasıdır. İşitme kaybı ve müzikal algı ilişkisi son yıllarda sıklıkla karşılaşılan bir araştırma konusudur. Çalışmalarda işitme kayıplı, işitme cihazı ve/veya koklear implant kullanıcısı bireylerin sahip olduğu müzikal algı farklı yönleriyle ele alınmıştır. Bu derlemenin amacı; işitme kayıplı, işitme cihazı ve/veya koklear implant kullanıcısı bireylerde müzik algısına ilişkin bilgileri ve güncel çalışmaları gözden geçirmek ve konuya ilişkin bakış açısı kazandırmaktır.

Anahtar Kelimeler: Müzikal algı, işitme kaybı, koklear implant, işitme cihazı.

\section{Music Perception in Individuals with Hearing Loss}

\begin{abstract}
Hearing loss is the inability of hearing. Musical perception is the perception of music. The relationship between hearing loss and musical perception has been a frequently encountered subject of research in recent years. In the studies, different aspects of the musical perception of individuals with hearing loss, hearing aid and/or cochlear implant users have been discussed. The aim of this review is to review the knowledge and current studies on the perception of music in individuals with hearing loss, hearing aid and/or cochlear implant users, and to gain perspective on the subject.
\end{abstract}

Keywords: Musical perception, hearing loss, cochlear implant, hearing aid.

\section{Derleme Makale (Review Article)}

Geliş / Received: 02.06.2021 \& Kabul / Accepted: 30.07.2021

DOI: https://doi.org/10.38079/igusabder.947027

* Arş. Gör., İstanbul Gelişim Üniversitesi, Sağllk Bilimleri Fakültesi, Odyoloji Bölümü, İstanbul, Türkiye, E-posta: caturk@gelisim.edu.tr ORCID https://orcid.org/0000-0002-0072-2703

** Arş. Gör., İstanbul Gelişim Üniversitesi, Sağllk Bilimleri Fakültesi, Odyoloji Bölümü, İstanbul, Türkiye, E-posta: azkoseoglu@gelisim.edu.tr ORCID https://orcid.org/oooo-0001-6462-3918 *** Dr. Öğr. Üyesi, İstanbul Gelişim Üniversitesi, Sağlık Bilimleri Fakültesi, Odyoloji Bölümü, İstanbul, Türkiye, E-posta: szeren@gelisim.edu.tr ORCID https://orcid.org/o000-0003-33467603 


\section{Giriș}

Müzik tını, ritim ve melodi gibi temel özelliklere sahip organize ses dizisi olarak tanımlanabilir . Türk Dil Kurumu (TDK) sözlüğü müziği "birtakım duygu ve düşünceleri belli kurallar çerçevesinde uyumlu seslerle anlatma sanatı” olarak tanımlamıştır². Müzik aynı zamanda, yaşama keyif katan, normal işiten bireyler için de, işitme kayıplı bireyler için de olumlu etkilere sahip bir unsurdur³.

Müziğe yapısal açıdan bakıldığında ritim, perde, melodi, tını şeklinde dört ana bileşeni bulunmaktadır. Ritim, temporal ilişsileri; perde ise spektral açıdan incelenerek harmonik zenginliği temsil eder. Farklı perdeye sahip seslerin sıralı bir șekilde bir araya gelmesi ile melodi oluşur ${ }^{4}$. Tını ise hem spektral hem de temporal düzlemde incelenir ve aynı perde, șiddet ve süreye sahip iki notayı birbirinden ayırmamızı sağlar5

İşitme kaybı, en genel tanımıyla işitme duyusunda meydana gelen tam ya da kısmi azalmadır. Dünya Sağlık Örgütü (DSÖ) 2021 yılının Mart ayında ilk Dünya İşitme Raporunu yayınlamıştır. Raporda, 2050 yılına kadar yaklaşık 2,5 milyar insanın işitme kaybı yaşayacağı bildirilmiştir. Bu, 2050 yılına kadar 4 kişiden 1’inin işitme problemi yaşayacağının tahmin edildiği anlamına gelmektedir6 ${ }^{6}$.

İşitme cihazları (İC) sesleri yükselten elektronik cihazlardır ve medikal ya da cerrahi olarak tedavi edilemeyen işitme kayıplarında önerilmektedir. Ișitme cihazlarının çevreden gelen sesleri toplamak, işlemlemek ve yükseltmek gibi temel fonksiyonları vardir7.

İşitme cihazlarında sinyal işleme ve fitting yöntemleri öncelikle konuşmanın anlaşılabilirliğini sağlamak üzere kurgulanmaktadır. İşitme cihazlarının müzik dinlemedeki etkinliğine öncelik verilmemesi işitme cihazı kullanıcılarının müzik dinlerken işitme cihazlarından memnun olmamalarına neden olabilir.

İşitme cihazı kullanıcısı profesyonel bir müzisyen ya da yalnızca müzik dinlemekten hoşlanan bir kişi olabilir. Her iki durumda da işitme cihazının elektronik ve elektroakustik parametreleri hem konuşma hem de müzik dinleme için uygun hale getirilebilir9. Koklear implantlar (Kİ) ise, ileri ve çok ileri derece işitme kayıplı, geleneksel işitme cihazlarından fayda göremeyen bireylerin işitsel rehabilitasyonunda kullanılan, ameliyat ile yerleştirilen, elektronik stimülasyon sağlayan protezlerdir ${ }^{10}$. İşitsel sinir liflerinin 
aktivasyonu için akustik sinyali elektrik uyaranlarına dönüştürürler ve böylece iç saç hücrelerinin işlevini yerine getirirler. İmplantasyon sonrasında bireylerin elektriksel uyarım ile normale yakın bir ișitme hassasiyetine sahip olabileceği bildirilmiştir ${ }^{11}$.

İşitmeyi iyileştirmek amacı ile işitme cihazı uygulamasında konuşmanın anlaşılabilirliğinin sağlanması ile iletişimin sağlanması birinci önceliktir. Doğal olarak konuşma genellikle müzik kadar yüksek bir ses düzeyinde gerçekleşmez. Ancak müzik güçlü bir kültürel unsur olmasının yanı sıra özellikle çocuk yaş grubunda önemli bir eğitim aracıdır. $\mathrm{Bu}$ derlemede işitme cihazı ve/veya koklear implant kullanıcısı bireylerde müzikal algıya dair güncel bilgi ve çalışmaların aktarılmasıyla alanda çalışan uzmanlara ve odyologlara konuya ilişkin farklı bir bakış açısı sunmak amaçlanmaktadır.

\section{Müzik Algısı}

Müzik algısını tanımlarken, müziğin tanımından faydalanılabilir. Müziğin perde, tını ve melodinin bileşenlerinden oluştuğu bildirilmiştir, bireyin bu bileşenleri algılaması ve analiz etmesi müzik algısını oluşturur ${ }^{12}$.

Müzikal algılamada süreç, işitsel kortekse gelen sesin frekansının, önceden öğrenilmiş anlamlı kalıplar içinde aranıp filtrelendikten sonra anlamlandırılması, yani müziğe dönüşmesi ile oluşur ${ }^{13}$.

Konuşma ve müziğin işitsel algısı, farklı sesleri, perdelerini, sürelerini, yoğunluklarını, tınılarını ve zaman içindeki değişimlerini ayırt etme yeteneğini içerir. Bu özellikler, kullanıcıların sesleri yorumlama ve anlamlandırma becerisini geliştirir ${ }^{14}$. Konuşmada olduğu gibi, müzik iç̧erisinde de hem spektral (uyaranın frekansına bağlı) hem de temporal (uyaranın zamanına bağlı) bilgiler bulunmaktadır ve bu bilgiler çok geniş bir frekans aralığında içerik bakımından zengin, kompleks ve çok hızlı bir biçimde iletilmektedir4.

Cross'a göre müzik sosyal yapıları modelleyen, gençlerin sosyal yetkinlik kazanmasını kolaylaştıran ve insan etkileşimi sağlayan bir araç olarak hizmet eder ${ }^{15}$. Müzik dinleyicilerinin müzikten alacağı zevki belirleyen bazı faktörler vardır. Müzik zevkini sağlayabilmek için müziğin karmaşık yapısı incelenmelidir. Müziğin karmaşık yapısı ise çeşitli türleri, enstrümanları, ses ve ritimleri kapsamasından kaynaklanmaktadır¹6,17. 


\section{İşitme Cihazı ve Koklear İmplant Kullanıcılarında Müzik Algısı}

Teknolojinin ve işitme eğitimlerinin gelişmesiyle, işitme kayıplı bireyler normal işiten bireylere yakın bir işitme algısına sahip olabilmektedir. Müzik algısı ise işitme cihazı ve koklear implant kullanıcısı bireyler için zorlayıcılı̆̆ını korumaktadır ${ }^{1,18,19}$.

İşitme cihazları gelişen cihaz teknolojisi ile doğal ses algısına yaklaşmaktadır, ancak tam anlamıyla doğal ses duyumunu sağlamada yetersiz kalabilir. Müzik algısı için yapılan değerlendirmede ise işitme cihazları koklear implanta göre daha iyi sonuç vermiştir ${ }^{20}$. Nyffeler'e göre işitme cihazı kullanıcılarında, yüksek frekanslı işitme kaybı yaygın görülen bir odyometrik konfigürasyondur ${ }^{21}$. Yüksek frekansları etkileyen işitme kaybı konuşmayı anlamayı etkilediği gibi bireylerin yaşam kalitesini arttıran müziğin anlaşılmasını ve tanımlanmasını da güçleştirebilir²2. İşitme cihazı teknolojisi geliştikçe, müzikal algının İC kullanan bireylerin yaşam kalitelerini iyi yönde etkileyebileceği düşünülmüss, müzikal algıya olan ilgi artmıştır¹5.

Madsen ve arkadaşlarının çalışmasında işitme cihazı kullanıcılarının büyük çoğunluğu müzik dinlemede işitme cihazının yararlı olduğunu ifade etmişlerdir. Ancak bir kısım işitme cihazı kullanıcısı ise müzik dinlerken distorsiyon, aşırı ses yüksekliği, yumuşak seslerin yetersiz işitilmesi ve ton kalitesinin azalması gibi sorunlar yaşamıştır. Bu çalışmanın sonuçları, yüksek ses seviyelerinde distorsiyonun önlenmesi, input ve output aralığının artırılması ve düşük frekansların düzenlenmesi ile işitme cihazı kullanıcılarında müzikal algının geliştirilebileceğini göstermektedir.

Yüksel'e göre koklear implantlardaki önemli gelişmelere rağmen Kİ kullanıcılarının büyük bir ç̧ğunluğu belki de konuşma seslerinden sonra en önemli sesler olan müzikal sesleri doğru bir şekilde algılamakta zorlanmaktadır.

Gürültü varlığında konușmanın anlașılması ve müzik algısı gibi beceriler üzerinde hassas temporal bilginin önemli bir etkisi vardır. Bu göz önüne alındığında, Kİ kullanıcılarının deneyimledikleri kısıtllılklar daha iyi anlașlmaktadır²3. Bu performans kısıtllı̆̆̆ının en belirgin sonuçları gürültülü ortamlarda konuş,manın net bir șekilde anlaşlamamass ${ }^{24-26}$ ve kısıtlı müzik algılama becerileri sebebiyle müzikten yeterince keyif alınamamasıdır ${ }^{27-}$ 29. Günümüzün koklear implant sistemleri ses işleme ve gürültü baskılama gibi çeşitli ek işlevlerle donatılmıştır. Çocuklarda işitme kaybının erken saptanması ve 
implantasyonun hızlı bir şekilde gerçekleştirilmesi, normale yakın konuşma ve dil gelişimine ulaşmalarını sağlamaktadır ${ }^{30}$.

Gürültüde konuşmayı anlamayı iyileştirmek, binaural işitmeyi sağlamak için bilateral (her iki kulağa da) implantasyon gerçekleştirilmelidir. Ardışık bilateral koklear implantasyon tercihinde mümkün olan en kısa zamanda ikinci implantasyon gerçekleştirilerek iyi bir işitme performansı elde etme şansı arttırılmalıdır3

Unilateral (tek taraflı) Kİ kullanan bireyler, bilateral (iki taraflı) implante edilenlere göre zamansal işaretlerin yanlış algılanması ve daha düşük konuşma çözünürlüğünden kaynaklanan bir güçlük çekmektedirler ${ }^{2}$. Koklear implant kullanıcılarının müzik deneyimi ve aldığı müzikal girdi normal işiten bireylerden farklıdır. İşitme kaybının ve dolayısıyla koklear implantların sebep olduğu sınırlandırmalar, işitsel girdilerin işlenmesini değiştirebilir. Bu sebeple çoğu Kİ kullanıcısı müziğin kendilerine tuhaf, gürültülü, doğal olmayan ve mekanik bir şekilde geldiğini bildirmiştir ${ }^{13}$.

\section{İşitme Kayıplı Bireylerde Müzik Algısı ile İlgili Yapılan Çalışmalar}

Postlingual (dil edinimi sonrası işitme kaybı) koklear implant kullanıcıları konuşmayı tanımada iyi sonuçlar elde etmektedirler, ancak kullanıcılar arası değişkenlik göstermekle birlikte koklear implant kullanımı sonrası müzik algısında düşüş gözlenmektedir ${ }^{17,27}$.

Çalışmalar koklear implant kullanıcılarının müziğin ritim ve tempo gibi özelliklerinde daha iyi bir algıya sahipken33-35, melodi, tını ve perde gibi özelliklerinde normal algıya yaklaşmakta güçlük çektiğini bildirmiştir35-38.

Perde algısındaki güçlüğün nedeni spektral çözünürlükteki sınırlılık olarak belirlenmiştir39-42,

Koklear implantta kullanılan elektrotların en uç apikal bölgeye ulaşamaması ve o bölgeyi uyaramaması bu sinırlılığı oluşturan bir durumdur ${ }^{42,43}$.

Ancak müzik eğitiminin perde algısındaki iyileştiriciliği ile koklear implant kullanıcıları bu sınırlanmanın etkisini azaltabilirler 44,45 .

Müzik eğitimi ile konuşma algısında da iyileşme belirtilmiştir, müzisyenlerde ve müzik eğitimi almış kişiler ile yapılan çalışmaların sonucu bunu destekler niteliktedir46-49. 
2021 yılında Ab Shukor ve ark. tarafından sistematik derleme ve meta-analiz çalışması yapılarak müzik eğitiminin işitme engelli bireylerde müzikal algının iyileştirilmesindeki etkinliğini değerlendirmek amaçlanmıştır. Çalışmanın sonucunda işitsel müzik eğitiminin işitme engelli dinleyicileri daha iyi müzikal algı seviyesine getirdiği ve eğitimin etkilerinin yaşa, eğitimin süresine ve kullanılan işitme cihazının türüne göre değiştiği bildirilmiştir. Müzik eğitimine başlamadan önce müzik deneyimi olan katılımcılar ile müzik deneyimi olmayanlar arasında müzikal algı iyileştirmeleri açısından önemli bir farklılık görülmemiştir.

Çalışmada vurgulanan diğer noktalar ise, işitme kaybı olan hastalarda müzik eğitiminin, işitsel eğitim olarak düşünülebileceği; pediatrik hastaların nöroplastisite ${ }^{14}$ etkisiyle yetişkinlere göre müzik eğitiminden daha fazla fayda sağlayabileceği; müzik eğitiminin koklear implant kullanıcılarında, bimodal kullanıcılara göre daha büyük bir etkiye sahip olabileceği ve müzik eğitiminin uzun sürmesinin (en az 12 ay) müzikal algı açısından daha iyi bir performans sağladığıdır5o.

Patel, müzik eğitiminin konuşmanın nöral kodlaması üzerindeki olumlu etkisini kaynak alarak geliş̧irdiği OPERA hipotezi ile müzik ile konuşma arasındaki ilişkiyi açıklamıştır ${ }^{1}$.

OPERA hipotezi “Overlap (müzik ve konuşmanın beyindeki kesişimi), Precision (müziğin tahmininde yüksek beyin seviyelerindeki kaynakları kullanması), Emotion (müziğin oluşturduğu duygular), Repetition (müzik aktivitelerindeki tekrarlar), Attention (müzik aktivitelerinin gerektirdiği dikkat)” kelimelerinin baş harflerinden oluşmaktadır. Hipoteze göre normal bir konuşma algısında ihtiyac, duyulacak nöral ağların çok daha üzerinde bir fonksiyon sağlanması için bu koşullar gereklidir. Yüksel'e göre dil ile müzik arasındaki kesişsim sayesinde müzik eğitiminden dil de fayda görmektedir 4 .

Müzik becerisini değerlendirmek için birtakım testler geliştirilmiştir. Primary Measures of Music Audiation testi Kİ kullanıcıları için adapte edilmiştir52. Daha sonra geliştirilen test bataryaları arasında Music Excerpt Recognition Test ve Iowa Music Perception and Apprasial Battery sayılabilir53,54.

Ancak bu bataryaların uygulanması uzun sürdüğünden ve uzman personel gerektirdiğinden yaygınlık kazanamamıştır. Daha sonraki dönemde yapılan birçok 
araștırmada, ç̧alışmanın yapıldığı laboratuvarda müzikal perde tanıma, tını veya melodi tanıma testleri özel olarak geliştirilmiştir. Fakat bu değiş̧enlik çalışmalar arasında karşılaștırma yapmayı güç̧eştirmiștir. 2008 yılında University of Washington Clinical Assessment of Music Perception (UW-CAMP) (Müzik Algısının Klinik Değerlendirmesi) Testi geliştirilmiștir. Geliştirilen bu test ile müzik algısını klinik amaçlarla doğru bir şekilde ölçmek ve klinik pratik içinde göreceli olarak kısa bir uygulama süresine sahip olması amaçlanmış ve geçerlilik çalışması Kang ve ark. (2009) tarafından yapılmıştır4,55. UW-CAMP testi içerisinde perde yönü ayırt etme, melodi tanıma ve tını tanıma alt testleri bulunmaktadır. Kİ kullanıcısı bu testi kendi kendine tamamlayabilmektedir.

D’Onofrio ve arkadaşlarının 2021 yılında yaptıkları çalışmada amaç; müzikal ses kalitesi, tını algılama ve konuşma tanımada bimodal (bir tarafta işitme cihazı diğer tarafta koklear implant kullanımı) fayda sağlamak için gerekli minimum ve optimum akustik bant genişliğini belirlemektir. Kİ olmayan kulakta rezidüel işitmeye sahip bireyler için önemli olan bimodal faydanın hem konuşma hem de müzik uyaranları için elde edilebileceği görülmüşsür. Bu çalışmada, artan akustik bant genişliğiyle tüm uyaranlar için performansta gelişime doğru bir eğilim gözlemlenmiştir. Hem müzik hem de konuşma uyaranları için geniş bant amplifikasyonunun bimodal işitmeye sahip bireylerde konuşma ve müzik algısı için en uygun olduğu bildirilmiştir ${ }^{56}$.

Gfeller ve ark., bilateral koklear implant kullanımının şarkıların sözlerinin ve müziğinin tanınması üzerinde olumlu bir etki sağladığını, işitme cihazı ve koklear implantın birlikte takıldığı bimodal kullanıcıların ise enstrümantal müziği daha iyi algıladığını ve daha çok keyif aldığını bildirmişlerdir57. Yayınlanmış literatürde Kİ kullanıcılarının müzik algılama becerilerinin normal ișiten bireylere göre daha kötü olduğunu gösteren birçok çalışma mevcuttur $20,27,37,53$.

Fowler ve ark. 2021'de yaptıkları çalışmada, işitsel durumun müzikal algılama ve gürültüde konuşma becerilerine etkisini dört müzik algılama görevi aracılı̆̆ıyla incelemiştir. Çalışma normal işiten bireylerin ve Kİ kullanıcılarının perde ve melodi özelliklerini, gürültüde konuşmayı ve farklı enstrümanları doğru algılama yetenekleriyle farklılık gösterip göstermediğini sorgulamaktadır. Kİ kullanıcılarının müziği ve konuşmayı normal işiten bireylerden daha kötü algıladıklarını ve tüm dinleyicilerde daha yüksek müzik algılama becerilerinin daha yüksek gürültü içindeki konuşma puanlarıyla ilişkili olduğunu göstermiştir 58 . 
2019 yılında Ahn ve ark. tarafından, Müzikal Algının Klinik Değerlendirmesi testinin Kore versiyonu (K-CAMP) ve müzik dinleme anketleri kullanılarak postlingual yetişkin koklear implant kullanıcılarının müzik algısındaki uzun vadeli değişikliklerin değerlendirilmesi amacıyla yapılan çalışmada, implantasyondan kısa bir süre sonra zayıf müzik algılama yeteneği olan Kİ kullanıcılarında, perde yönü ayırt etme ve zaman tanıma yeteneğinin eğitim olmadan geliştiği gözlemlenmiştir59.

Müzik Algı Testi (MPT) Uys ve Van Dijk tarafından geliştirilen bir müzikal algılama değerlendirme testidir. Şahlı ve ark. 2019 yılında, işitme kayılı bireylerin müzik performanslarını ölçme imkânı sağlayan bu testin Türkçe adaptasyon ve normalizasyonunu gerçekleştirerek Türkçe bir müzikal algılama testi geliştirmişlerdir ${ }^{15,60}$.

Dritsakis ve arkadaşlarının 2017 yılında yürüttükleri bir çalışmada, yetişkin Kİ kullanıcılarında müziğin yaşam kalitesi üzerine etkisi Quality of Life (QoL) anketi ile incelenmiştir. Çalışmada; müziğin yetişkin Kİ kullanıcılarında fiziksel, psikolojik ve sosyal açıdan birçok katkısının bulunduğu; Kİ kullanıcılarının müzik deneyimlerindeki iyileşmenin yaşam kalitesinde iyileşmelere yol açabileceği ve müziğin rehabilitasyon ihtiyacını destekleyebileceği bildirilmiştir.

Müziğin geçmişteki önemli olayları ve anılarını hatırlatması, özellikle daha önce normal işiten ve müzik deneyimi olan postlingual işitme kayıplı Kİ kullanıcıları tarafından önemli bulunmuştur. Müziğin olumlu duygular yaratmasının yanı sıra izolasyon ve yalnızlık gibi olumsuz duyguları azalttığı da bildirilmiştir.

İşitme kaybından sonra müziği tekrar duyabilmek, sosyal aktivitelere katılmak için gereken güveni ve normallik duygusunu yaratmıştır ve bu durum Kİ kullanıcılarının benlik saygısı üzerinde olumlu bir etkiye sahiptir.

Psikolojik sağlık üzerindeki olumlu etkilerinin aksine, bazı Kİ kullanıcılarının aşina oldukları müziği tanıma ve yeni müzikleri takip etmede yaşadıkları zorlukların, düşük ses kalitesi ile birlikte hoş olmayan duygulara neden olduğu ve benlik saygılarını olumsuz etkilediği de bildirilmiştir. Kİ kullanıcıları tarafından bildirilen bir diğer olumsuz durum, konuşmayı maskeleyen ve iletişimi zorlaştıran fon müziğinin (restoranlarda veya barlarda) varlığıdır. Kİ kullanıcıları tarafından, ritimle birlikte hareket etmenin gerekli olduğu daha zorlu dinleme ortamlarında (fitness ve dans dersleri gibi) ritmi takip etme 
zorluğu özgüven eksikliğine neden olmuştur. Kİ kullanıcıları, perdeleri iyi duyamamanın bir sonucu olarak, şarkı söylerken akort yapmanın zor olduğunu ve bu durumun korolarda şarkı söylemelerini engellediğini bildirmiştir. Ayrıca kullanıcılar müzikle bilişsel düzeyde etkileşimde bulunduklarını ve müziği bir eğitim kaynağı ve yeni beceriler öğrenme firsatı olarak ifade etmiştir.

QoL müziğin işitmeye yönelik faydalarını kulak çınlamasını hafifletme, hafızayı güçlendirme, normallik duygusu uyandırma ve müziğin eğitimde kullanılması olarak belirlemiştir. Çalışma müzik odaklı yeni Kİ teknolojilerinin kullanımını ve müzikle yapılan işitme eğitimi yoluyla yetişkin Kİ kullanıcılarının müzik deneyimini iyileştirmenin önemini vurgulamıştır ${ }^{61}$.

Dritsakis ve arkadaşlarının 2017 yılında yürüttükleri bir diğer çalışmada ise, bu çalışmanın devamı olarak müzik algısına yönelik Müzikle İlgili Yaşam Kalitesi Anketi (MuRQoL) geliştirilmiştir. MuRQoL anketi, müzik algısının, katılımının ve bunların müzik ile yapılan işitsel rehabilitasyona öncülük etme potansiyeline sahip yetişkin Kİ kullanıcıları için öneminin güvenilir ve geçerli bir ölçüsüdür62.

Literatürde Kİ kullanıcılarının, ifadeler ve sorular arasında ayrım yapmak gibi, prosodik (konuşmanın vurgu, perde, tonlama, duraksama gibi özellikleri) ipuçlarını algılamada da sıklıkla güçlük çektiğini gösteren çalışmalar mevcuttur ${ }^{63,64}$.

Jung ve ark. tarafından yapılan çalışmada ise prelingual Kİ kullanıcısı çocukların müzik algılama performansı, postlingual Kİ kullanıcısı yetişkinler ile karşılaștırılmıştır. Çalışma sonucunda melodi ve tını algısında prelingual Kİ kullanıcısı çocukların çok daha düşük performans sergiledikleri görülmüştür. Çocuklarda görülen bu daha kötü performansın sebebi ise zamansal işleme yeteneklerinde maturasyona bağlı oluşan gecikmedir 65 .

Yapılan bir diğer çalışmada, koklear implant kullanıcılarının müzik enstrümanlarını doğru tanıma oranı \% 45 olarak bulunmuştur, normal işiten bireylerde ise bu oran \% 94.2'dir55.

2019 yılında Clinical Assessment of Music Perception (CAMP) (Müzik Algısının Klinik Değerlendirmesi) testinin ülkemizde kullanılabilmesine yönelik bir ön çalışma gerçekleştirilmiştir. Türk kültürüne uygun, müzik algısını değerlendirme amacıyla yapılan TR-CAMP testinin ön çalışması sonucunda, beklenildiği gibi normal işiten 
bireyler Kİ kullanıcılarına göre çok daha yüksek bir performans sergilemişlerdir. TRCAMP testi ülkemizde gelecekte Kİ veya İC kullanıcıları ile yapılabilecek müzik algılama çalışmaları için önemli bir araçtır4.

Kİ kullanıcılarında tını algısını değerlendiren çalışmalarda katılımcılara aynı notaları aynı süre ve şiddette çalan farklı enstrümanlar dinletilmiş ve bunları ne ölçüde tanıyabildikleri incelenmiştir. Çalışmalarda müzik eğitimi ve tecrübesi olan Kİ kullanıcılarının enstrüman tanımada daha başarılı olduğu görülmüştür66.

2021 yılında Spitzer ve ark. tarafından yapılan çalışmada amaç, koklear implantta sinyal işleme için önemli olan elektriksel uyaran ile müzikal algıdaki melodik aralık bozulmasını ölçmektir. Bimodal ve tek taraflı işitme kaybı olan Kİ kullanıcılarında melodik aralık sıralaması ölçülmüştür. Tek taraflı işitme kaybı olan ve bimodal kullanıcılar arasında aralık bozulmasında hiçbir fark bulunamamış, bu da kök notalarda ve test edilen aralıklarda yeterli akustik işitilebilirlik olduğunu göstermişstir. Hem akustik hem de elektrik işitmede geniş bir frekans aralı̆̆ına sahip olan tek taraflı işitme kayıplı Kİ kullanıcıları, müziğin akustik ve elektriksel uyaranla sağlanan işitme ile dinlerken tek başına akustik işitme ile dinlemekten çok daha keyifli olduğunu bildirmektedir 67.

2021'de Zhou ve ark. tarafından yapılan çalışmanın amacı ise, müzik algısı ve ton tanımanın bimodal faydalarını ölçmek ve Mandarince konuşan tek taraflı Kİ ve bimodal Kİ vakaları arasındaki ilişkiyi araştırmaktır. Çalışma sonucunda bimodal Kİ kullanıcıları, tek taraflı Kİ kullanan katılımcılardan daha iyi müzik algılama ve ton tanıma becerisi elde etmiştir. Kİ kullanıcılarının tonu tanıma veya müziği algılama yeteneğini geliştirmek için tasarlanmış teknikler (müzik eğitimi gibi), günlük dinleme becerileri için de faydalı olacaktır68.

\section{Sonuç ve Öneriler}

Günümüzde işitme kayıplı bireyler gelişen işitme cihazı ve koklear implant teknolojisi ve işitme eğitiminde görülen gelişmelerle, normal işiten bireylerinkine benzer bir işitme algısına sahip olabilmektedir. Ancak müzik algısı, işitme cihazı ve koklear implant kullanıcısı bireyler için zorlayıcılı̆̆ını korumaktadır. Müzik eğitimi programları, İC ve Kİ kullanıcılarında müzik algısını iyileştirmede etkili bir yöntem olup işitme kayılı bireylerde işitsel ve müzikal algıyı iyileştirmek için işitsel rehabilitasyon yaklaşımı olarak 
uygulanabilir. Kİ kullanıcılarının müzik deneyimlerindeki iyileşme yaşam kalitesini de yükseltebilir.

Cihazların sebep olduğu sınırlamaların bir sonucu olarak işitme kayıplı bireyler müziği algılamada ve müzikten keyif almada zorluk yaşamalarına rağmen, müziği günlük yaşamlarında kullanır ve yaşamlarının çeşitli alanlarında normal işiten yetişkinlere benzer şekilde müzikten fayda sağlarlar.

\section{KAYNAKLAR}

1. McDermott HJ. Music perception with cochlear implants: a review. Trends Amplif. 2004;8(2):49-82. doi:10.1177/108471380400800203.

2. Türk Dil Kurumu. Güncel Türkçe Sözlük. https://sozluk.gov.tr. Erişim tarihi 19 Nisan 2021.

3. Lassaletta L, Castro A, Bastarrica M, et al. Does music perception have an impact on quality of life following cochlear implantation?. Acta Otolaryngol. 2007;127(7):682-686. doi:10.1080/00016480601002112.

4. Yüksel M. Koklear implant kullanıcılarında spektral ve temporal işitsel işlemleme ile müzik algısı arasındaki ilişki [doktora tezi]. İstanbul, Türkiye: Odyoloji ve Konuşma Bozuklukları, Marmara Üniversitesi Sağlık Bilimleri Enstitüsü; 2019.

5. Sonn M, Acoustical Society of America \& American National Standards Institute. American national standard psychoacoustical terminology. New York: The Institute;1973.

6. World Health Organization. World report on hearing. https://www.who.int/publications/i/item/world-report-on-hearing.Yayınlanma tarihi 3 Mart 2021. Erişim Tarihi 19 Nisan 2021.

7. Dillon H. Hearing Aids. 2nd ed. New York: Thieme Medical Journals; 2012.

8. Madsen SM, Moore BC. Music and hearing aids. Trends Hear. 2014;18:2331216514558271. Published 2014 Oct 31. doi:10.1177/2331216514558271.

9. Chasin M, Russo FA. Hearing AIDS and music. Trends Amplif. 2004;8(2):35-47. doi:10.1177/108471380400800202. 
10. Gfeller K, Mallalieu RM, Mansouri A, et al. Practices and Attitudes That Enhance Music Engagement of Adult Cochlear Implant Users. Front Neurosci. 2019;13:1368. doi:10.3389/fnins.2019.01368.

11. Clark GM. Personal reflections on the multichannel cochlear implant and a view of the future. $J$ Rehabil Res Dev. 2008;45(5):651-693. doi:10.1682/jrrd.2007.05.0064.

12. Bozkır, B. Profesyonel müzisyenlerde müzik algısı farklılıkları; bir FMRI çalışması. [doktora tezi]. İzmir, Türkiye: Müzik Bilimleri, Dokuz Eylül Üniversitesi Güzel Sanatlar Enstitüsü; 2009.

13. Düşünmez, İ. Koklear İmplantlı Çocuklarda Müzikal Duygulanımın Değerlendirilmesi. [yüksek lisans tezi]. Ankara, Türkiye: Odyoloji, Hacettepe Üniversitesi Sağlık Bilimleri Enstitüsü; 2019.

14. Gfeller K. Music-based training for pediatric CI recipients: A systematic analysis of published studies. Eur Ann Otorhinolaryngol Head Neck Dis. 2016;133 Suppl 1 (Suppl 1):S50-S56. doi:10.1016/j.anorl.2016.01.010.

15. Uys M, van Dijk C. Development of a music perception test for adult hearing-aid users. S Afr J Commun Disord. 2011 Oct;58:19-47. doi: 10.4102/sajcd.v58i1.38. Erratum in: S Afr J Commun Disord. 2012 Dec;59:26. PMID: 22216557.

16. Gfeller K, Christ A, Knutson J, Witt S, Mehr M. The effects of familiarity and complexity on appraisal of complex songs by cochlear implant recipients and normal hearing adults. $J$ Music Ther. 2003;40(2):78-112. doi:10.1093/jmt/40.2.78.

17. Looi V, Gfeller K, Driscoll V. Music appreciation and training for cochlear implant recipients: a review. Semin Hear. 2012;33(4):307-334. doi:10.1055/s-00321329222.

18. Kohlberg GD, Mancuso DM, Chari DA, Lalwani AK. Music Engineering as a Novel Strategy for Enhancing Music Enjoyment in the Cochlear Implant Recipient. Behav Neurol. 2015;2015:829680. doi:10.1155/2015/829680.

19. Gfeller K, Oleson J, Knutson JF, Breheny P, Driscoll V, Olszewski C. Multivariate predictors of music perception and appraisal by adult cochlear implant users. $J \mathrm{Am}$ Acad Audiol. 2008;19(2):120-134. doi:10.3766/jaaa.19.2.3. 
20. Looi V, McDermott H, McKay C, Hickson L. Music perception of cochlear implant users compared with that of hearing aid users. Ear Hear. 2008;29(3):421-434. doi:10.1097/AUD.obo13e31816aodob.

21. Nyffeler, M. Study finds that non-linear frequency compression boosts speech intelligibility. Hearing Journal. 2008;61(12):22-26.doi: 10.1097/O1.HJ.0000343022.22475.98.

22. Glista D, McDermott H. Phonak Sound Recover: A breakthrough in enhancing intelligibility. Naida Product Information. Stafa, Switzerland: Phonak Hearing Systems; 2008. https://www.audiologyonline.com/releases/soundrecoverbreakthrough-in-enhancing-intelligibility-3719. Yayınlanma tarihi 6 Haziran 2008. Erişim tarihi 25 Nisan 2021.

23. Moon IJ, Hong SH. What is temporal fine structure and why is it important? Korean J Audiol. 2014;18(1):1-7. doi:10.7874/kja.2014.18.1.1.

24. Armstrong M, Pegg P, James C, Blamey P. Speech perception in noise with implant and hearing aid. Am J Otol. 1997;18(6 Suppl):S140-S141.

https://europepmc.org/article/med/9391635. Erişim tarihi 20 Nisan 2021.

25. Hochberg I, Boothroyd A, Weiss M, Hellman S. Effects of noise and noise suppression on speech perception by cochlear implant users. Ear Hear. 1992;13(4):263-271. doi:10.1097/00003446-199208000-0ooo8.

26. Van Hoesel RJ, Tyler RS. Speech perception, localization, and lateralization with bilateral cochlear implants. J Acoust Soc Am. 2003;113(3):1617-1630. doi:10.1121/1.1539520.

27. Drennan WR, Oleson JJ, Gfeller K, et al. Clinical evaluation of music perception, appraisal and experience in cochlear implant users. Int J Audiol. 2015;54(2):114123. doi:10.3109/14992027.2014.948219.

28. Gfeller K, Christ A, Knutson JF, Witt S, Murray KT, Tyler RS. Musical backgrounds, listening habits, and aesthetic enjoyment of adult cochlear implant recipients. J Am Acad Audiol. 2000;11(7):390-406. https://www.audiology.org/sites/default/files/journal/JAAA 1107 05.pdf. Erişim tarihi 20 Nisan 2021.

29. Migirov L, Kronenberg J, Henkin Y. Self-reported listening habits and enjoyment of music among adult cochlear implant recipients. Ann Otol Rhinol Laryngol. 2009;118(5):350-355. doi:10.1177/000348940911800506. 
30. Lenarz T. Cochlear implant - state of the art. GMS Curr Top Otorhinolaryngol Head Neck Surg. 2018;16:Doc04. Published 2018 Feb 19. doi:10.3205/ctooo0143.

31. Illg A, Giourgas A, Kral A, Büchner A, Lesinski-Schiedat A, Lenarz T. Speech comprehension in children and adolescents after sequential bilateral cochlear implantation with long interimplant interval. Otol Neurotol. 2013;34(4):682-689. doi:10.1097/MAO.obo13e31828bb75e.

32. Hopyan-Misakyan TM, Gordon KA, Dennis M, Papsin BC. Recognition of affective speech prosody and facial affect in deaf children with unilateral right cochlear implants. Child Neuropsychol. 2009;15(2):136-146. doi:10.1080/09297040802403682.

33. Cooper WB, Tobey E, Loizou PC. Music perception by cochlear implant and normal hearing listeners as measured by the Montreal Battery for Evaluation of Amusia. Ear Hear. 2008;29(4):618-626. doi:10.1097/AUD.obo13e318174e787.

34. Kim I, Yang E, Donnelly PJ, Limb CJ. Preservation of rhythmic clocking in cochlear implant users: a study of isochronous versus anisochronous beat detection. Trends Amplif. 2010;14(3):164-169. doi:10.1177/1084713810387937.

35. Kong YY, Cruz R, Jones JA, Zeng FG. Music perception with temporal cues in acoustic and electric hearing. Ear Hear. 2004;25(2):173-185. doi:10.1097/o1.aud.0000120365.97792.2f.

36. Fujita S, Ito J. Ability of nucleus cochlear implantees to recognize music. Ann Otol Rhinol Laryngol. 1999;108(7 Pt 1):634-640. doi:10.1177/000348949910800702.

37. Gfeller K, Turner C, Mehr M, et al. Recognition of familiar melodies by adult cochlear implant recipients and normal-hearing adults. Cochlear Implants Int. 2002;3(1):29-53. doi:10.1179/cim.2002.3.1.29.

38. Drennan WR, Rubinstein JT. Music perception in cochlear implant users and its relationship with psychophysical capabilities. $J$ Rehabil Res Dev. 2008;45(5):779789. doi:10.1682/jrrd.2007.08.0118.

39. Croghan NBH, Duran SI, Smith ZM. Re-examining the relationship between number of cochlear implant channels and maximal speech intelligibility. $J$ Acoust Soc Am. 2017;142(6):EL537. doi:10.1121/1.5016044.

40. Madsen SMK, Whiteford KL, Oxenham AJ. Musicians do not benefit from differences in fundamental frequency when listening to speech in competing speech backgrounds. Sci Rep. 2017;7(1):12624. doi:10.1038/s41598-017-12937-9. 
41. Shannon RV, Fu QJ, Galvin J 3rd. The number of spectral channels required for speech recognition depends on the difficulty of the listening situation. Acta Otolaryngol Suppl. 2004;(552):50-54. doi:10.1080/03655230410017562.

42. Rubinstein JT. How cochlear implants encode speech. Curr Opin Otolaryngol Head Neck Surg. 2004;12(5):444-448. doi:10.1097/01.moo.0000134452.24819.co.

43. Stakhovskaya O, Sridhar D, Bonham BH, Leake PA. Frequency map for the human cochlear spiral ganglion: implications for cochlear implants. $J$ Assoc Res Otolaryngol. 2007;8(2):220-233. doi:10.1007/s10162-007-0076-9.

44. Fu QJ, Galvin JJ 3rd, Wang X, Wu JL. Benefits of music training in mandarinspeaking pediatric cochlear implant users. J Speech Lang Hear Res. 2015;58(1):163-169. doi:10.1044/2014_JSLHR-H-14-0127.

45. Galvin JJ, Eskridge E, Oba S, Fu QJ. Melodic contour identification training in cochlear implant users with and without a competing instrument. Semin Hear. 2012;33(4), 399-409. doi:10.1055/s-0032- 1329227.

46. Kraus N, Skoe E, Parbery Clark A, Ashley R. Experience-induced malleability in neural encoding of pitch, timbre, and timing. Ann N Y Acad Sci. 2009;1169:543557. doi:10.1111/j.1749-6632.2009.04549.x.

47. Parbery Clark A, Skoe E, Lam C, Kraus N. Musician enhancement for speech-innoise. Ear Hear. 2009;30(6):653-661. doi:10.1097/AUD.obo13e3181b412e9.

48. Patel AD. Language, music, syntax and the brain. Nat Neurosci. 2003;6(7):674681. doi:10.1038/nn1082.

49. Tzounopoulos T, Kraus N. Learning to encode timing: mechanisms of plasticity in the auditory brainstem. Neuron. 2009;62(4):463-469. doi:10.1016/j.neuron.2009.05.002.

50. Shukor NFA, Lee J, Seo YJ, Han W. Efficacy of music training in hearing aid and cochlear implant users: A systematic review and meta-analysis. Clin Exp Otorhinolaryngol. 2021;14(1):15-28. doi:10.21053/ceo.2020.00101.

51. Patel AD. Why would musical training benefit the neural encoding of speech? The OPERA Hypothesis. Front Psychol. 2011;2:142. Published 2011 Jun 29. doi:10.3389/fpsyg.2011.00142. 
52. Gordon EE. Developmental music aptitude as measured by the primary measures of music audiation. Psychology of Music. 1979;7(1):42-49. doi:10.1177/030573567971005.

53. Gfeller K, Lansing CR. Melodic, rhythmic, and timbral perception of adult cochlear implant users. J Speech Hear Res. 1991;34(4):916-920. doi:10.1044/jshr.3404.916.

54. Gfeller K, Olszewski C, Rychener M, et al. Recognition of "real-world" musical excerpts by cochlear implant recipients and normal-hearing adults. Ear Hear. 2005;26(3):237-250. doi:10.1097/00003446-200506000-00001.

55. Kang R, Nimmons GL, Drennan W, et al. Development and validation of the University of Washington clinical assessment of music perception test. Ear Hear. 2009;30(4):411-418. doi:10.1097/AUD.ob013e3181a61bco.

56. D'Onofrio KL, Gifford RH. Bimodal Benefit for Music Perception: Effect of Acoustic Bandwidth. J Speech Lang Hear Res. 2021;64(4):1341-1353. doi:10.1044/2020_JSLHR-20-00390.

57. Gfeller K, Jiang D, Oleson JJ, Driscoll V, Knutson JF. Temporal stability of music perception and appraisal scores of adult cochlear implant recipients. $J$ Am Acad Audiol. 2010;21(1):28-34. doi:10.3766/jaaa.21.1.4.

58. Fowler SL, Calhoun H, Warner-Czyz AD. Music perception and speech-in-noise skills of typical hearing and cochlear implant listeners. Am J Audiol. 2021;30(1):170-181. doi:10.1044/2020_AJA-20-00116.

59. Ahn J, Ryu G, Cho YS. Long-term Changes in Musical Perception in Korean Cochlear Implant Patients. Otol Neurotol. 2019;40(3):312-320. doi:10.1097/MAO.0000000000002098.

60. 60.Sahli AS, Belgin E, Uys M. A musical perception test for people with hearing loss: Turkish adaptation and normalization of the Music Perception Test (MPT). Niger J Clin Pract. 2019;22(12):1669-1674. doi:10.4103/njcp.njcp_279_19.

61. Dritsakis G, van Besouw RM, O' Meara A. Impact of music on the quality of life of cochlear implant users: a focus group study. Cochlear Implants Int. 2017;18(4):207-215. doi:10.1080/14670100.2017.1303892.

62. Dritsakis G, van Besouw RM, Kitterick P, Verschuur CA. A music-related quality of life measure to guide music rehabilitation for adult cochlear implant users. Am J Audiol. 2017;26(3):268-282. doi:10.1044/2017_AJA-16-0120. 
63. Kalathottukaren RT, Purdy SC, Ballard E. Prosody perception and musical pitch discrimination in adults using cochlear implants. Int $J$ Audiol. 2015;54(7):444-452. doi:10.3109/14992027.2014.997314.

64. Chatterjee M, Peng SC. Processing Fo with cochlear implants: Modulation frequency discrimination and speech intonation recognition. Hear Res. 2008;235(1-2):143-156. doi:10.1016/j.heares.2007.11.004.

65. Jung KH, Won JH, Drennan WR, et al. Psychoacoustic performance and music and speech perception in prelingually deafened children with cochlear implants. Audiol Neurootol. 2012;17(3):189-197. doi:10.1159/000336407.

66. Galvin JJ 3rd, Fu QJ, Oba S. Effect of instrument timbre on melodic contour identification by cochlear implant users. J Acoust Soc Am. 2008;124(4):EL189EL195. doi:10.1121/1.2961171.

67. Spitzer ER, Galvin JJ 3rd, Friedmann DR, Landsberger DM. Melodic interval perception with acoustic and electric hearing in bimodal and single-sided deaf cochlear implant listeners. Hear Res. 2021;400:108136. doi:10.1016/j.heares.2020.108136.

68. Zhou Q, Gu X, Liu B. Bimodal benefits in Mandarin-speaking cochlear implant users for music perception and tone recognition. Acta Otolaryngol. 2021;141(4):359-366. doi:10.1080/00016489.2020.1782984. 